\title{
Polish version of the Questionnaire for Eudaimonic Well-Being - three factors rather than one
}

\section{BACKGROUND}

In their conception of well-being, Waterman et al. refer to the eudaimonist philosophy in which well-being is the active development of human best potentials and perceiving them as personally expressive.

\section{PARTICIPANTS AND PROCEDURE}

The main objective of the present research was to determine the psychometric properties of the Polish adaptation of the Questionnaire for Eudaimonic Well-Being (QEWB) and to verify the structure of the construct. Four studies were performed with a total of 2273 participants. The psychometric properties of the Polish adaptation of the QEWB were proven. To verify the factorial structure, exploratory and confirmatory factor analysis was used, as well as exploratory structural equation modeling. The factor analysis showed that although assessing the general score of the QEWB is justified, the three-factorial structure fit best (CFI from .929 to .963 and RMSEA from
.038 to .052 in all four studies). The criterion validity of the three factors was tested using the Mental Health Continuum-Short Form (MHC-SF), measures of procrastination (PPS, NAPS), personality traits (IPIP-BMF-20) and grit (Grit-S).

\section{RESULTS}

The results confirm the factorial structure of eudaimonic well-being reported in the literature, which is not fully compatible with the originally described structure.

\section{CONCLUSIONS}

The current study showed the importance of considering eudaimonic well-being as a multidimensional and multifactorial construct.

\section{KEY WORDS}

eudaimonic well-being; measurement equivalence; the Questionnaire for Eudaimonic Well-Being; QEWB; ESEM

Organisation - Cardinal Stefan Wyszyński University in Warsaw, Poland

Authors' Contributions - A: Study design - B: Data collection · C: Statistical analysis · D: Data interpretation ·

E: Manuscript preparation · F: Literature search · G: Funds collection

CORRESPONDING AUTHOR - Maria Kłym-Guba, Cardinal Stefan Wyszyński University in Warsaw,

1/3 Wóycickiego Str., 00-001 Warsaw, Poland, e-mail: mariaklym@gmail.com

TO CITE ThIS ARTICLE - Kłym-Guba, M., \& Karaś, D. (2018). Polish version of the Questionnaire for Eudaimonic

Well-Being - three factors rather than one. Health Psychology Report, 6(3), 273-283. doi: https://doi.org/10.5114/

hpr.2018.75684

RECEIVED 06.02.2018 · REVIEWED · 21.03.2018 · ACCEPTED 22.04.2018 · PUBLISHED 07.06.2018 


\section{BACKGROUND}

In the early framings of well-being, a wide concept called subjective well-being (SWB) was defined (Diener, Lucas, \& Oishi, 2002) as the cognitive and emotional evaluation of one's life. It covers positive emotional experience, a low intensity of negative moods, and a high level of satisfaction with life that includes both emotional responses to events and cognitive judgments relating to life fulfillment. The sources of well-being
Maria Kłym-Guba, Dominika Karaś are not differentiated in this paradigm, the consequence of which is the measurement of psychological well-being, which provides information on the overall level of satisfaction.

As presented in Waterman's work, eudaimonic well-being (EWB) refers to "the quality of life derived from the development of a person's best potentials and their application in the fulfillment of personally expressive, self-concordant goals" (Waterman et al., 2010, p. 41). Eudaimonic well-being is considered here as a capacious but consistent and undivided construct. Following Schutte and colleagues' (Schutte, Wissing, \& Khumalo, 2013) doubt on that assumption, this paper presents an attempt to verify the unidimensionality of eudaimonic well-being.

\section{HEDONISM AND EUDAIMONISM}

The theories presented in the literature (Ryan \& Deci, 2001; Luyckx, Soenens, Goosens, Beckx, \& Wouters, 2008; Ryff, 1989; Vleioras \& Bosma, 2005; Waterman et al., 2010; Negru \& Crocetti, 2010; Hofer, Busch, \& Kaertner, 2011; Hofer, Kaertner, Chasiotis, Busch, $\&$ Kiessling, 2007) represent two ways to understand well-being and delineate two overlapping perspectives and ways to pursue well-being: hedonic and eudaimonic.

Hedonism is a view assuming that well-being is associated with experiencing pleasant feelings (Crisp, 2008) - it is thus a desire to maximize enjoyment and minimize pain, which refers to the subjective experience of pleasure and feeling good, no matter how the pleasure is provided. The hedonic tradition is closely linked to emotional well-being, satisfaction with life, and experiencing a positive affect (Diener, 1984). This approach, however, does not seem to fully describe well-being by equating the various sources of happiness.

The eudaimonic perspective emerges from Aristotle's philosophy and it goes beyond experiencing pleasure and subjective well-being. It is also focused on assessing positive human functioning in life, a higher level of psychosocial integration and a good life (Waterman et al., 2010). Aristotelian eudaimonia is the highest good - happiness consisting not only of pleasure but also of virtue (Ryff, 1989). Well-being in this tradition is not only pleasure but also the realization of human potentials (Ryan \& Deci, 2001). Eu- daimonia is a state of complete and reasonable justifiable contentment and satisfaction with one's life. In accordance with this understanding, well-being lies in the implementation and fulfillment of one's own true human nature (Ryan \& Deci, 2001; Waterman et al., 2010).

Eudaimonia is the highest achievement of nature (understood as striving to meet life tasks in the best possible way, in accordance with the ideal of true humanity). According to the classical Hellenic philosophy, true happiness can be found by leading a virtuous life and doing things worth doing. For Plato and Socrates, eudaimonia was the state of perfection of one's life (Frede, 2009; Kraut, 2012). Aristotle developed their ideas - for him, eudaimonia was a state of mind reached by meeting all the needs in balanced way, both carnal and spiritual (Robinson, 1989). Aristotle emphasized that not all desires are worth fulfilling because although some of them may give subjective pleasure, they will not provide wellness. He argued that the realization of a human's potential is the highest aim in life.

The psychological understanding of eudaimonic well-being, held in the mentioned philosophical tradition, goes beyond the sense of pleasure in life and includes a higher degree of psychosocial integration. It is not the opposite of hedonic well-being, which consists primarily of temporary affect, but rather its complement - eudaimonic well-being also includes pleasure. Nevertheless, its main feature is the sense of importance and development - a more durable and lasting kind of happiness (Bauer, McAdams, $\&$ Pals, 2008). Thus, eudaimonic well-being refers to the quality of life achieved through the development of one's resources and capabilities and using them to achieve life purposes (Waterman et al., 2010). In terms of eudaimonia, well-being is not subjective satisfaction but an objectively good life. In relation to subjective well-being, happiness (hedonia) is seen as an aim in itself, a particular result that was sought and to which the person aspired. Using the perspective of eudaimonic well-being, subjectively experienced and expressed feelings are a byproduct of taking action, which is consistent with the development and expression of one's abilities and pursuing internal purposes. The motive in eudaimonist action is the value of the performed activity itself and not a subjective experience.

\section{THE QUESTIONNAIRE FOR EUDAIMONIC WELL-BEING}

To measure well-being conceptualized as it is framed in eudaimonic philosophy, the Questionnaire for Eudaimonic Well-Being - QEWB (Waterman et al., 2010) - was developed. Initially, the item pool contained 25 statements referring to six interdepen- 
dent categories with high philosophical-psychological ties. The final version of the QEWB consists of 21 self-reported items selected on the basis of feedback from participants in a pilot study. The aspects of eudaimonic well-being included in the QEWB measure are self-discovery, the perceived development of one's best potentials, a sense of purpose and meaning in life, intense involvement in activities, investment of significant effort, and enjoyment of activities as personally expressive. Waterman describes the above as "inter-related categories with strong philosophical-psychological linkages" (Waterman et al., 2010, p. 44); however, he does not clearly indicate which items match which category and just gives one example of an item for each category. Therefore, the presented six categories are treated as six aspects of a one-factorial construct, and only a total score is considered as an indicator of eudaimonic well-being.

The unifactorial structure of the QEWB was examined by the authors using confirmatory factor analyses (CFA). The analyses were conducted on created parceled indicators to represent the QEWB items. In two samples considered in the study, the unifactorial structure was proven by satisfactory fit indicators.

Doubt surrounding the idea of the unidimensionality of EWB has already been described by Schutte et al. (2013), who noted the lack of exploratory factor analysis in Waterman's study before confirming the one-factorial structure. They also emphasized that using parceling to represent the QEWB items could have suggested that a higher order factor underlies the scale, and the suspicion that a more precise understanding of QEWB dimensionality could have emerged if the data was analyzed at the item level. The researchers conducted a number of analyses revealing satisfactory fit for models with three and four factors. Preparing the Polish adaptation of the QEWB was one of our main aims, in addition to verifying the psychometric properties of the tool, acknowledging that the QEWB measures eudaimonic well-being, and verifying the structure issue. When adapting the questionnaire into Polish, double translation was used. The process of adapting the questionnaire into Polish included double translation and semantic consultations with a native speaker.

\section{CURRENT STUDY}

On the basis of reports in the current literature, we assumed a multifactorial structure of eudaimonic well-being. Consequently, we chose to extract a number of factors, all with high reliability (Schutte et al., 2013). The first hypothesis posed in this study was H1: there are three EWB factors distinguished in exploratory analyses (Sense of Purpose, Purposeful Personal Expressiveness, Effortful Engagement), and they show high reliability. At the same time, we expected the differentiation of relationships occurring between these factors and psychological variables considered in the literature to be closely connected with well-being, such as mental health. Additionally, personality and the temperamental aspects of individual differences turned out to be more strongly associated with well-being than life circumstances (Lucas \& Diener, 2009). This type of finding would strengthen the confirmation of the multifactorial structure of the construct. Thus, we formulated the following hypotheses: H2: The particular EWB factors correlate differently with psychological, social, and emotional well-being in Keyes' conceptualization of the Mental Health Continuum; H3: The particular EWB factors correlate differently with procrastination indicators; and H4: The particular EWB factors correlate differently with grit and personality traits. The study also investigated the measurement equivalence of a three-factorial solution across all four studies. Hypothesis 5 was H5: there is a measurement invariance between the three-factorial structure achieved in the four presented studies.

\section{PARTICIPANTS AND PROCEDURE}

A total of four studies were evaluated to investigate the connections between eudaimonic well-being measured with the QEWB and some related aforementioned constructs. Additionally, we verified the measurement equivalence of QEWB factors on the basis of data obtained in studies of four samples presented in Table 1.

Table 1

Specification and descriptive statistics of groups in the studies

\begin{tabular}{lcccc}
\hline Study number & $N$ & Gender distribution & Age & Data collecting method \\
\hline S1 & 488 & $37 \%$ male & $M=21.50(S D=1.95)$ & $\begin{array}{c}\text { Offline (paper-and-pencil), } \\
\text { group interviewing } \\
\text { Offline (paper-and-pencil), } \\
\text { group interviewing }\end{array}$ \\
S3 & 279 & $49 \%$ male & $M=20.79(S D=1.87)$ & $\begin{array}{c}\text { Offline (paper-and-pencil), } \\
\text { group interviewing }\end{array}$ \\
S4 & 406 & $24 \%$ male & $M=23.64(S D=6.32)$ & Online, group interviewing \\
\hline
\end{tabular}




\section{MEASURES}

The Questionnaire for Eudaimonic Well-Being. The main tool administered to the participants was the Questionnaire for Eudaimonic Well-Being - QEWB (Waterman et al., 2010; Polish adaptation: Kłym, Karaś, Najderska, \& Cieciuch, 2014). The tool consists of 21 self-reported items (see Table 5). There are 14 items written in a positive direction, implying a high level of eudaimonic well-being, and 7 items in a negative direction, indicating a lack of eudaimonic well-being and reverse scoring. The participants answered the items on a 5-point Likert-type scale, choosing one of the possible answers, from 0 - strongly disagree to 4 - strongly agree. In our research using the Polish adaptation of the QEWB, in all four conducted studies, we achieved a similar reliability coefficient ( $\alpha=.87 / .87 / .84 / .86)$ to Waterman's research $(\alpha=.86)$. The Cronbach's $\alpha$ coefficients are given for all the studies in which the tool has been used and are listed in the following order: Study 1, Study 2, Study 3, and Study 4.

The Mental Health Continuum-Short Form. The Polish adaptation of the MHC-SF (Keyes, 2002) by Karaś, Cieciuch, and Keyes (2014) is a 14-item questionnaire that measures three aspects of well-being: psychological (6 items), social (5 items) and emotional (3 items). The response option adopted in the short form of the MHC enables the measurement of the frequency of experiencing each sign of mental health during the past month (6-point scale, from never to every day). Reliability achieved for the tool was: $\alpha=.86 / .86 / .87 / .89$ for psychological $\mathrm{w}-\mathrm{b}$, $\alpha=.79 / .78 / .78 / .83$ for social $\mathrm{w}-\mathrm{b}, \alpha=.84 / .83 / .83 / .86$ for emotional $\mathrm{w}-\mathrm{b}$, and $\alpha=.90 / .90 / .91 / .93$ for total MHC score. MHC-SF was used in all four samples.

The Pure Procrastination Scale. The Polish adaptation of the PPS (Steel, 2010) by Stępien and Cieciuch (2013) is a short scale intended to capture the general notion of dysfunctional delay. It includes 12 items with a 5-point Likert scale (ranging from 1 - completely untrue to 5 - completely true) on which respondents mark the accuracy with which each statement describes him or her. We achieved a reliability coefficient $\alpha=.92 / .90$. The PPS was used in Sample 1 and Sample 2.

The New Active Procrastination Scale. The NAPS (Choi \& Moran, 2009; Polish adaptation: Stępień $\&$ Cieciuch, 2014) is an alternative measuring tool of procrastination as a dysfunctional, self-effacing behavior. It is composed of 16 statements referring to four dimensions of active procrastination: a person's affective preference for time pressure, the cognitive decision to procrastinate, the behavioral capacity to meet deadlines, and the ability to achieve satisfactory outcomes. The response scale in this measure contains 7 points (ranging from 1 - completely agree to 7 - completely disagree). The reliability achieved for the total score in this measure was $\alpha=.84$. The NAPS was used only in Sample 2.

Big Five Measure - The International Personality Item Pool. We used one of the tools constructed in the International Personality Item Pool (IPIP) battery. IPIP-BMF-20 (Donnellan, Oswald, Baird, \& Lucas, 2006) is a 20 -item questionnaire measuring five basic personality traits in terms of the lexical tradition: extraversion, agreeableness, conscientiousness, emotional stability, and intellect. The Polish adaptation was prepared by Topolewska, Skimina, Strus, Cieciuch, and Rowiński (2014), and the participant's task was to rate with a 5-point scale how aptly the statements describe him or her (from 1 - very inaccurate to 5 - very accurate). Cronbach's $\alpha$ coefficients for the traits were as follows: $\alpha=.86$ for extraversion, $\alpha=.67$ for agreeableness, $\alpha=.76$ for conscientiousness, $\alpha=.77$ for emotional stability, and $\alpha=.62$ for intellect. IPIP-BMF-20 was used only in Sample 1.

The Short Grit Scale. Grit-S (Duckworth \& Quinn, 2009; Polish adaptation: Wyszyńska, Ponikiewska, Karaś, Najderska, \& Cieciuch, 2014) is a measure of grit construct, defined as trait-level perseverance and passion for long-term goals. The tool includes 8 statements referring to two facets of grit: interest and effort; however, it is also possible to calculate the overall result. The participants respond on a scale of 5 points (from very much like me to not like me at all). The reliability coefficient achieved for the Polish adaptation of Grit-S was $\alpha=.79(\alpha=.70$ for Interest and $\alpha=.69$ for Effort subscales). Grit-S was only used in Sample 2.

\section{RESULTS}

\section{FACTORIAL STRUCTURE OF EUDAIMONIC WELL-BEING}

We aimed to determine whether the items on the QEWB formed a single common factor. A commonly used strategy in that case is to use confirmatory factor analysis (CFA) to ensure findings first obtained in exploratory factor analysis (EFA). However, in CFA, each observable indicator usually loads only one latent factor, and cross loadings are also possible. As a result, the correlation between latent factors can be flattened (Brown, 2015). Thus, the recent literature postulates using other methods while investigating the factor structure of multi-dimensional constructs, such as eudaimonic well-being. Exploratory structural equation modeling (ESEM; Asparouhov \& Muthen, 2009) omits the disadvantage of CFA mentioned above and integrates two common approaches: exploratory and confirmatory factor analyses. It can be treated as a type of exploratory factor analysis but is carried out within a structural equation modeling approach. 
Table 2

ESEM fit indicators for three factors of eudaimonic well-being in comparison to alternatively tested models with one and two factors

\begin{tabular}{|c|c|c|c|c|c|}
\hline \multicolumn{6}{|c|}{ One-factor model } \\
\hline & $\chi^{2}$ & $d f$ & $\mathrm{CFI}$ & RMSEA & SRMR \\
\hline Study 1 & 813.90 & 170 & .699 & .092 & .086 \\
\hline Study 2 & 488.82 & 170 & .763 & .085 & .078 \\
\hline Study 3 & 661.69 & 170 & .678 & .090 & .086 \\
\hline Study 4 & 1718.34 & 170 & .718 & .092 & .076 \\
\hline \multicolumn{6}{|c|}{ Two-factor model } \\
\hline & $\chi^{2}$ & $d f$ & $\mathrm{CFI}$ & RMSEA & SRMR \\
\hline Study 1 & 484.74 & 151 & .844 & .071 & .061 \\
\hline Study 2 & 275.23 & 151 & .907 & .056 & .050 \\
\hline Study 3 & 453.91 & 151 & .807 & .075 & .059 \\
\hline Study 4 & 920.02 & 151 & .854 & .070 & .053 \\
\hline \multicolumn{6}{|c|}{ Three-factor model } \\
\hline & $\chi^{2}$ & $d f$ & $\mathrm{CFI}$ & RMSEA & SRMR \\
\hline Study 1 & 256.48 & 133 & .942 & .046 & .035 \\
\hline Study 2 & 182.82 & 133 & .963 & .038 & .034 \\
\hline Study 3 & 236.01 & 133 & .934 & .046 & .037 \\
\hline Study 4 & 508.78 & 133 & .929 & .052 & .031 \\
\hline
\end{tabular}

In the ESEM procedure, all items are specified to load on all the factors, which provides the ability to freely estimate cross-loadings, and consequently makes the estimates more accurate, e.g., more realistic factor intercorrelations. Cross-loadings are not constrained to be zero as they are in CFA. Thus, researchers suggest that ESEM adequately addresses the limitations of CFA and currently is the most appropriate procedure to capture the structure of multi-dimensional constructs (Joshanloo, 2015).

We ran the ESEM procedure in Mplus statistical software and found more satisfactory fit coefficients than in CFA for the three-factor solution (CFA model fit indices for S1/S2/S3/S4 were respectively: $\mathrm{CFI}=832 / .883 / .833 / .820$ and RMSEA $=.078 / .063 / .071 / .080)$. To indicate structural validity, we used the comparative fit index (CFI), for which values of .95 and higher indicate good fit, and the root mean square error of approximation (RMSEA) with its associated $90 \%$ confidence interval (CI), for which values smaller than .08 mark satisfactory model fit (Albright \& Park, 2006-2009). A comparison of fit indicators for models with one, two, and three factors assessed in Mplus is presented in Table 2.
The first distinguished factor consists of 6 items (numbers: 2, 4, 9, 11, 16, 21) focused on having a clear feeling of one's own life purpose. The second factor, which brings together the largest number of items (numbers: 1, 5, 6, 8, 13, 14, 15, 17, 18), refers to expressiveness and a sense of being the "real me" in action. The last factor is composed of 5 items (numbers: 3, 7, $12,19,20)$, which are all reversed. Its content is connected with a lack of perseverance and difficulty in engaging. Loadings for the factors achieved in four conducted studies and assigned items' contents are shown in Table 5. The range of acquired correlation indicators for the three factors was .36-.71, and specific values are given in Table 3.

Table 3

Correlations obtained between three QEWB factors in all studies

\begin{tabular}{lccc}
\hline & $\begin{array}{c}\text { Factor 1/ } \\
\text { Factor 2 }\end{array}$ & $\begin{array}{c}\text { Factor 1/ } \\
\text { Factor 3 }\end{array}$ & $\begin{array}{c}\text { Factor 2/ } \\
\text { Factor 3 }\end{array}$ \\
\hline Study 1 & .66 & .56 & .64 \\
Study 2 & .71 & .52 & .68 \\
Study 3 & .69 & .36 & .46 \\
Study 4 & .68 & .64 & .70 \\
\hline
\end{tabular}

QEWB three factors 
Except for a few items $(1,4,6,10)$, the factor-item fit exactly coincides with the three-factor model obtained by Schutte et al. (2013). Moreover (omitting problematic item 10), two of the three mentioned items -1 and 6 - are characterized by high item loading for factor 2 but also for factor 1, according to the findings of Schutte et al. To describe the achieved factors, we drew on their naming. The term for the first distinguished factor is Sense of Purpose. The items assigned to this factor describe WaMaria terman's sense of purpose and meaning in life but Kłym-Guba, also self-discovery. Factor 2 was called Purposeful Dominika Karaś Personal Expressiveness. It consists of items related to the other four aspects designated by Waterman: the development of best potential, involvement in activities, investment of effort and enjoyment of activities. Factor 3, named Effortful Engagement, is composed only of reversed items referring to a lack of diligence or zeal, which should be noted in interpreting results of analyses. The varied relationships of these factors with different psvchological vari-

Table 4

Model fit indices of 3-factorial QEWB structure on three levels of measurement invariance

\begin{tabular}{lcc}
\hline $\begin{array}{l}\text { Measurement } \\
\text { invariance }\end{array}$ & RMSEA & CFI \\
\hline $\begin{array}{l}\text { Configural } \\
\text { level }\end{array}$ & .046 & .940 \\
Metric level & .045 & .934 \\
Scalar level & .045 & .930 \\
\hline
\end{tabular}

Note. RMSEA - root mean square error of approximation, ideally < 0.80; CFI - comparative fit index, ideally $>0.90$. ables, proving the legitimacy of their characterization, are presented in Table 6.

\section{MEASUREMENT EQUIVALENCE OF QEWB}

Measurement invariance can be used to study whether a given measure is interpreted in a conceptually similar manner by various groups (Vandenberg \& Lance, 2000). As the research included four samples, we were able to ensure that the same construct was being measured across all groups of participants. To test the measurement invariance of eudaimonic well-being data collected across all studies, we proved the measurement equivalence of QEWB on all levels: configural, metric, and scalar. The analyses were conducted in Mplus statistical software. The standard indicator of model fit for measurement invariance is presented in Table 4.

In conclusion, analyses conducted in Mplus statistical software also showed the stability of the 3-factorial model achieved in ESEM. Factor loadings for all four studies are included in Table 5.

\section{RELIABILITY}

In our research using the Polish adaptation of the QEWB, we achieved a similar reliability coefficient of the total score as Waterman's research: $\alpha=.71$, $\alpha=.71, \alpha=.83, \alpha=.86$ (arranged with respect to the study number). Additionally, in most cases, we obtained satisfactory reliability of newly distinguished factors in each of the four studies. The comparison of Cronbach's $\alpha$ coefficients is shown in Table 6.

Table 5

QEWB item loadings for 3 factors (Study 1/Study 2/Study 3/Study 4)

\begin{tabular}{|c|c|c|c|}
\hline & Factor 1 & Factor 2 & Factor 3 \\
\hline $\begin{array}{l}\text { 2. I believe I have discovered } \\
\text { who I really am. }\end{array}$ & $.88 / .61 / .62 / .66$ & $.01 / .23 / .28 / .18$ & $-.16 /-.00 / .02 /-.07$ \\
\hline $\begin{array}{l}\text { 9. I can say that I have found my } \\
\text { purpose in life. }\end{array}$ & $.89 / .77 / .65 / .84$ & $.01 / .21 / .28 / .00$ & $-.10 /-.00 /-.04 /-.00$ \\
\hline $\begin{array}{l}\text { 21. I believe I know what I was } \\
\text { meant to do in life. }\end{array}$ & $.76 / .75 / .58 / .84$ & $-.02 / .13 / .28 /-.02$ & $-.02 /-.01 / .01 /-.04$ \\
\hline $\begin{array}{l}\text { 15. When I engage in activities } \\
\text { that involve my best } \\
\text { potentials, I have this sense of } \\
\text { really being alive. }\end{array}$ & $-.04 /-.02 /-.04 /-.02$ & $.63 / .60 / .73 / .60$ & $.24 / .20 / .05 / .30$ \\
\hline $\begin{array}{l}\text { 18. It is important to me that } \\
\text { I feel fulfilled by the activities } \\
\text { that I engage in. }\end{array}$ & $.03 / .00 /-.02 / .02$ & $.59 / .61 / .74 / .60$ & $.31 / .10 / .00 / .17$ \\
\hline
\end{tabular}


13. I believe it is important to know how what I'm doing fits

$-.05 /-.05 /-.08 / .05$ with purposes worth pursuing.

17. I find a lot of the things I do are personally expressive for me.

14. I usually know what I should do because some actions just feel right to me.

$. \mathbf{4 3} / .19 / .15 / .33$

$.37 / .54 / .64 / .38$

$-.12 /-.05 /-.06 /-.01$

QEWB three factors

6. I believe I know what my best potentials are and I try to develop them whenever possible.

8. I feel best when I'm doing something worth investing a great deal of effort in.

1. I find I get intensely involved in many of the things I do each day.

5. It is more important that I really enjoy what I do than that other people are impressed by it.

4. My life is centered around a set of core beliefs that give meaning to my life.

19. If something is really difficult, it probably isn't worth doing. (R)

12. I can't understand why some people want to work so hard on the things that they do. (R)

7. Other people usually know better what would be good for me to do than I know myself. (R)

11. As yet, I've not figured out what to do with my life. (R)

$.80 / .75 / .60 / .77$

$.16 / .09 / .05 / .24$

$.43 / .46 / .29 / .52$

$-.01 / .16 / .00 / .05$

$.28 / .24 / .45 / .18$

$-.31 /-.06 /-.02 /-.23$

$.15 / .16 / .34 / .16$

$.40 / .42 / .55 / .47$

16. I am confused about what my talents really are. $(\mathrm{R})$

3. I think it would be ideal if things came easily to me in my life. ( $R$ ) invested in the things that I do. (R)

ote. Probability $p<.05$ is in bold. Loadings under .30 are in grey.

Item 10, as problematic due to double negation included, was omitted and it was not taken into account during the analysis. 
Table 6

Reliability coefficients (Cronbach's $\alpha$ ) for eudaimonic well-being factors

\begin{tabular}{lcccc}
\hline & Study 1 & Study 2 & Study 3 & Study 4 \\
\hline QEWB total score & .71 & .71 & .83 & .86 \\
Sense of purpose & .86 & .87 & .79 & .85 \\
Purposeful personal expressiveness & .81 & .82 & .82 & .80 \\
Effortful engagement & .71 & .63 & .68 & .66 \\
\hline
\end{tabular}

Maria

Kłym-Guba,

Dominika Karaś

\section{CRITERION VALIDITY}

The total score from the QEWB correlated significantly with all the scales from the Mental Health Continuum-Short Form (MHC-SF), and, in accordance with the hypothesis that QEWB measures eudaimonic well-being, the strongest correlation was confirmed for the scale of psychological well-being, which is also considered as the eudaimonic component of well-being. The correlations obtained in all four studies are presented in Table 7. The table also contains correlations of the QEWB (total score as well as three distinguished factors) achieved for additional measures, including such constructs as procrastination, personality traits and grit.

Similarly, as in the original research (Waterman et al., 2010), well-being measured with the QEWB was moderately correlated with personality traits (positively with agreeableness, conscientiousness, extraversion, intellect, and negatively with neuroticism). As far as procrastination is concerned, the QEWB scores correlate negatively with pure procrastination measured with PPS (treated as negative procrastination linked with postponing the activity) and positively with procrastination measured with NAPS (this kind of procrastination is called "active" and is treated as adaptive). Grit is the construct treated as the perseverance and passion for long-term goals, and thus its correlations with QEWB dimensions are also positive.

\section{DISCUSSION}

Waterman et al. (2010) described certain aspects of eudaimonic well-being, such as self-discovery, perceived development of one's best potentials, a sense of purpose and meaning in life, intense involvement in activities, investment of significant effort, and enjoyment of activities, as personally expressive. However, with respect to the structure, the authors do not distinguish any components or sub-factors, and they present it as multidimensional; however, a one-factor construct can be assessed by a short, 21-item QEWB scale. A Polish adaptation of the questionnaire developed by Kłym et al. (2014) is characterized by satisfactory psychometric properties and properties.
The aims of the presented study were to question the unifactoriality of the QEWB and to verify the actual factorial structure of the tool. The one-factor structure of eudaimonic well-being proposed by Waterman et al. (2010) was accepted and adopted by the researchers and has been widely used in research in the field of positive psychology. In further studies, however, it was questioned whether it is justified to treat eudaimonic well-being only as a holistic and indivisible construct. Working on the Polish adaptation of the questionnaire, we reached the conclusion leading to a slightly different structure of eudaimonic well-being than originally assumed. It turned out that although it is certainly reasonable to analyze the overall general score of the QEWB, the construct can be explicitly divided into some components. The independent verification of the structure of eudaimonic well-being carried out by Schutte et al. (2013) in South African samples also revealed that there are three factors distinguishable within it (Factor 1: Sense of Purpose, Factor 2: Purposeful Personal Expressiveness, Factor 3: Effortful Engagement). To maintain consistency in the terminology, for the three factors obtained in our research, we adopted the names proposed by the researchers.

Verifying the factorial structure, we applied standard analyses usually reported in psychological research, as well as the statistical procedure that is mostly recommended to investigate multidimensional constructs. Thus, we were able to acquire some information that might have been missed due to analyses applied in previous research. The factors of eudaimonic well-being are conceptually related, and the opinion that they cannot be empirically distinguishable may be connected not with the actual state but, as Joshanloo (2015) notes, with the statistic strategies and procedures used in data analyses. The present research tends to confirm this claim that, in other research, the intercorrelations between factors of well-being may have been overestimated due to the inherent limitations of traditional CFA.

Distinguishing three factors in the QEWB, we obtained high Cronbach's $\alpha$ coefficients and proved satisfactory reliability for all the factors. Additionally, the associations with other psychological variables are varied among the three factors of eudaimonic well-being, which strengthens the finding that the 


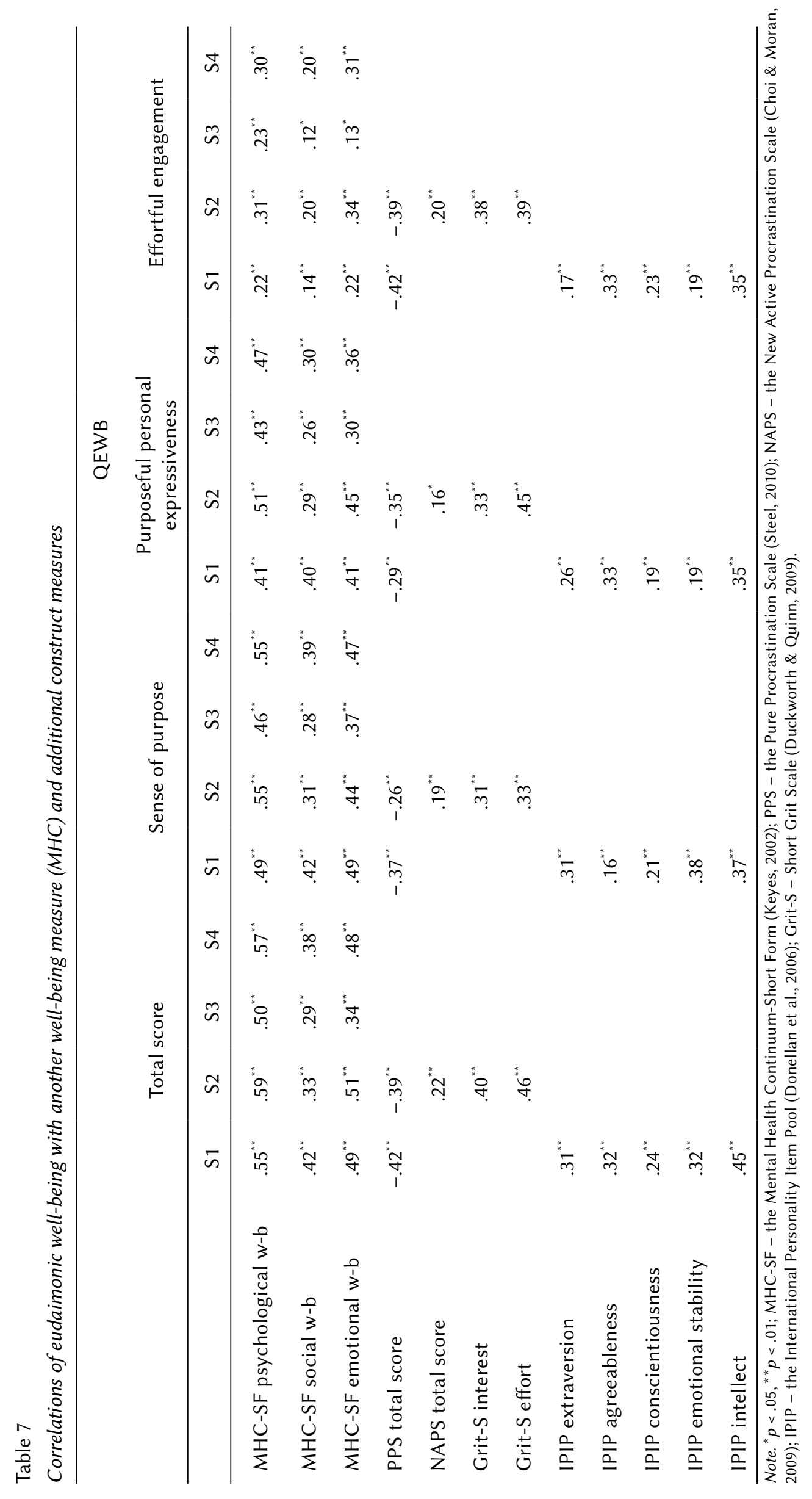

QEWB

three factors 
QEWB does not measure a unidimensional construct. The associations of eudaimonic well-being factors with psychological well-being from the MHC-SF and procrastination measures are in agreement with the hypotheses. Moderate correlations with personality and grit traits support the conclusion that high eudaimonic well-being is not related systematically with these relatively stable human characteristics.

As the research included studies on four independent samples, it also allowed us to conduct a verification of measurement invariance of the achieved structure across all groups. We proved the measurement equivalence of the three distinguished QEWB factors across all four studies.

The current study showed the importance of considering eudaimonic well-being as a multidimensional and multifactorial construct, as it supports the findings demonstrated in the recent literature concerning the structure of eudaimonic well-being. Further research using the Polish adaptation of the QEWB is in progress.

\section{REFERENCES}

Albright, J. J. \& Park, H. M. (2006-2009). Confirmatory factor analysis using Amos, LISREL, Mplus, SAS/ STAT CALIS. Working Paper. The University Information Technology Services (UITS) Center for Statistical and Mathematical Computing, Indiana University. http://www.indiana.edu/ statmath/stat/ all/cfa/index.html.

Asparouhov, T., \& Muthen, B. (2009). Exploratory structural equation modeling. Structural Equation Modeling, 16, 397-438.

Bauer, J. J., McAdams, D. P., \& Pals, J. L. (2008). Narrative identity and eudaimonic well-being. Journal of Happiness Studies, 9, 81-104.

Brown, T. A. (2015). Confirmatory factor analysis for applied research. London: The Guilford Press.

Choi, J. N., \& Moran, S. V. (2009). Why not procrastinate? Development and validation of a New Active Procrastination Scale. The Journal of Social Psychology, 149, 195-211.

Crisp, R. (2008). Well-being. In E. N. Zalta (Ed.), The Stanford Encyclopedia of Philosophy. (http:// plato.stanford.edu/archives/win2008/entries/ well-being).

Diener, E. (1984). Subjective Well-Being. Psychological Bulletin, 95. Available at SSRN: https://ssrn com/abstract $=2162125$

Diener, E., Lucas, R. E., \& Oishi, S. (2002). Subjective well-being. The science of happiness and life satisfaction. In C. R. Snyder \& S. J. Lopez (Eds.), Handbook of positive psychology (pp. 63-73). New York: Oxford University Press.

Donnellan, M. B., Oswald, F. L., Baird, B. M., \& Lucas, R. E. (2006). The Mini-IPIP scales: Tinyyet-ef- fective measures of the Big Five Factors of personality. Psychological Assessment, 18, 192-203.

Duckworth, A. L., \& Quinn, P. D. (2009). Development and validation of the Short Grit Scale (Grit-S). Journal of Personality Assessment, 91, 166-174.

Frede, D. (2009). Nicomachean Ethics VIII. 11-12: Pleasure. In C. Natali (Ed.), Aristotle: Nicomachean Ethics, Book VII: Symposium Aristotelicum (pp. 183-207). New York: Oxford University Press.

Hofer, J., Busch H., \& Kaertner, J. (2011). Self-regulation and well-being: the influence of identity and motives. European Journal of Personality, 25, 211-224.

Hofer, J., Kaertner, J., Chasiotis, A., Busch, H., \& Kiessling, H. (2007). Socio-cultural aspects of identity formation: the relationship between commitment and well-being in student samples from Cameroon and Germany. Identity: an International Journal of Theory and Research, 7, 265-288.

Joshanloo, M. (2015). Revisiting the empirical distinction between hedonic and eudaimonic aspects of well-being using exploratory structural equation modeling. Journal of Happiness Studies, 17, 2023-2036. Published online: 2015-10-23.10. doi: 1007/s10902-015-9683-z

Karaś, D., Cieciuch, J., \& Keyes, C. L. M. (2014). The Polish adaptation of the Mental Health Continuum-Short Form (MHC-SF). Personality and Individual Differences, 69, 104-109.

Keyes, C. L. M. (2002). The mental health continuum: From languishing to flourishing in life. Journal of Health and Social Behavior, 43, 207-222.

Kłym, M., Karaś, D., Najderska, M., \& Cieciuch, J. (2014). Polish Version of the Questionnaire for Eudaimonic Well-Being (QEWB). 28 $8^{\text {th }}$ International Congress of Applied Psychology, Paris, France. 8-13 July.

Kraut, R. (2012). Aristotle's Ethics. In E. N. Zalta (ed.), The Stanford Encyclopedia of Philosophy. http:// plato.stanford.edu/entries/aristotle-ethics/

Lucas, R. E., \& Diener, E. (2009). Personality and subjective well-being. The science of well-being. Social Indicators Research Series, 37, 75-102. doi: 10.1007/978-90-481-2350-6_4

Luyckx, K., Soenens, B., Goosens, L., Beckx, K., \& Wouters, S. (2008). Identity exploration and commitment in late adolescence: correlates of perfectionism and mediating mechanisms on the pathway to well-being. Journal of Social and Clinical Psychology, 27, 336-361.

Negru, O., \& Crocetti, E. (2010). Dimensions of well-being and identity development in Romanian and Italian emerging adults: a cross-cultural analysis. EHPS, Cluj, Romania.

Robinson, D. N. (1989). Aristotle's psychology. New York: Columbia University Press.

Ryan, R. M., \& Deci, E. L. (2001). On happiness and human potentials: a review of research on hedonic and eudaimonic well-being. Annual Review of Psychology, 52, 141-166. 
Ryff, C. D. (1989). Happiness is everything, or is it? Explorations on the meaning of psychological well-being. Journal of Personality and Social Psychology, 57, 1069-1081.

Schutte, L., Wissing, M. P., \& Khumalo, I. P. (2013). Further validation of the questionnaire for eudaimonic well-being (QEWB). Psychology of Well-Being: Theory, Research and Practice, 3, 3. http://www.psywb.com/content/3/1/3

Steel, P. (2010). Arousal, avoidant and decisional procrastinators: Do they exist? Personality and Individual Differences, 48, 926-934.

Stępień, M., \& Cieciuch, J. (2013). Pure Procrastination Scale. Unpublished manuscript. Warsaw: UKSW.

Stępień, M., \& Cieciuch, J. (2014). New Active Procrastination Scale. Unpublished manuscript. Warsaw: UKSW.

Topolewska, E., Skimina, E., Strus, W., Cieciuch, J., \& Rowiński, T. (2014). Krótki kwestionariusz do pomiaru Wielkiej Piątki IPIP-BFM-20 [The short questionnaire for measuring Big Five - IPIPBFM-20]. Roczniki Psychologiczne, 17, 367-384.

Vandenberg, R. J., \& Lance, C. E. (2000). A review and synthesis of the measurement invariance literature: suggestions, practices, and recommendations for organizational research. Organizational Research Methods, 3, 4-70.

Vleioras, G., \& Bosma, A. H. (2005). Are identity styles important for well-being? Journal of Adolescence, 28, 397-409.

Waterman, A. S., Schwartz, S. J., Zamboanga, B. L., Ravert, R. D., Williams, M. K., Agocha, V. B, Kim, S. Y., \& Donnellan, M. B. (2010). The Questionnaire for Eudaimonic Well-Being: Psychometric properties, demographic comparisons, and evidence of validity. The Journal of Positive Psychology, 5, 41-61.

Wyszyńska, P., Ponikiewska, K., Karaś, D., Najderska, M., \& Cieciuch, J. (2014). The Short Grit Scale. Unpublished manuscript. Warsaw: UKSW. 